\title{
Host Genes Involved in Nodulation Preference in Common Bean (Phaseolus vulgaris)-Rhizobium etli Symbiosis Revealed by Suppressive Subtractive Hybridization
}

\author{
Eitel Peltzer Meschini, ${ }^{1}$ Flavio Antonio Blanco, ${ }^{1}$ María Eugenia Zanetti, ${ }^{1}$ María Pía Beker, \\ Helge Küster, ${ }^{2}$ Alfred Pühler, ${ }^{2}$ and O. Mario Aguilar ${ }^{1}$ \\ ${ }^{1}$ Instituto de Biotecnología y Biología Molecular, Facultad de Ciencias Exactas, Universidad Nacional de La Plata, \\ 1900-La Plata, Argentina; ${ }^{2}$ Institute for Genome Research and Systems Biology, CeBiTec, Bielefeld University, \\ D-33594 Bielefeld, Germany
}

Submitted 22 October 2007. Accepted 4 December 2007.

Common bean cultivars are nodulated preferentially by Rhizobium etli lineages from the same center of host diversification. Nodulation was found to be earlier and numerous in bean plants inoculated with the cognate strain. We predicted that analysis of transcripts at early stages of the interaction between host and rhizobium would identify plant genes that are most likely to be involved in this preferential nodulation. Therefore, we applied a suppressive subtractive hybridization approach in which cDNA from a Mesoamerican cultivar inoculated with either the more- or less-efficient strain of $\boldsymbol{R}$. etli was used as the driver and the tester, respectively. Forty-one independent tentative consensus sequences (TCs) were obtained and classified into different functional categories. Of 11 selected TCs, 9 were confirmed by quantitative reverse-transcriptase polymerase chain reaction. Two genes show high homology to previously characterized plant receptors. Two other upregulated genes encode for Rab11, a member of the small GTP-binding protein family, and HAP5, a subunit of the heterotrimeric CCAAT-transcription factor. Interestingly, one of the TCs encodes for an isoflavone reductase, which may lead to earlier Nod factor production by specific strains of rhizobia. The transcript abundance of selected cDNAs also was found to be higher in mature nodules of the more efficient interaction. Small or no differences were observed when an Andean bean cultivar was inoculated with a cognate strain, suggesting involvement of these genes in the strain-specific response. The potential role of these genes in the early preferential symbiotic interaction is discussed.

Additional keywords: legume, root hair

Symbiosis in legume-rhizobium interactions is associated with changes in the morphology and physiology of the root to form a new organ, the nodule, where nitrogen is fixed from the atmosphere. This is a highly specific interaction, where few host-rhizobium strain combinations can lead to successful root

Corresponding author: O. Mario Aguilar;

E-mail: aguilar@biol.unlp.edu.ar

Pv-RHS24-01 to Pv-RHS24-41 sequences are available at GenBank under consecutive accession numbers EY457907 to EY457947. colonization. Recognition of particular rhizobium strains by a plant has significant impacts on nodulation efficiency and field competitiveness, as well as on soil fertility, plant foliage, and seed production of the plant. Thus, animal and human diets ultimately are affected.

The nodulation process is initiated by an exchange of chemical signals between both partners, beginning with the production of isoflavonoids by the plant when availability of fixed nitrogen is low. Presence and perception of these molecules in the rhizosphere lead to the production of Nod factor (NF), a lipochitooligosaccharide produced by strains of rhizobium (Long 1996). In addition to NF, other bacterial cell surface components, such as oligo- and polysaccharides, were proposed to act as microbial signals that are important for nodulation (Becker et al. 2005). This chemical communication allows for the recognition and colonization by specific strains of bacteria without triggering prolonged defense responses in plant roots. Upon recognition, root hairs change their shape to entrap bacteria by invagination of the plasma membrane. Bacteria then enter the root through a tubular structure called the infection thread (IT). At the same time, nodule primordia start to differentiate and will incorporate the bacteroids by endocytosis once the IT reaches the primordium. Mature nodules contain bacteroids that will use the energy provided by the plant to convert $\mathrm{N}_{2}$ to ammonium (Cullimore et al. 2001).

Perception of microbial signals leads to changes in hormone balances in the zone of nodule formation. Recently, Murray and associates (2007) and Tirichine and associates (2007) have demonstrated that activation of a cytokinin signaling pathway initiates cortical cell division, leading to the formation of nodule primordium. In addition to cytokinins, a role of auxins during the autoregulation of nodulation has been proposed (de Billy et al. 2001; van Noorden et al. 2006). Inhibitors of auxin action or treatment with high levels of auxins led to a reduced number of nodules in Medicago truncatula. In contrast, exogenous application of a low concentration of auxins increased nodule number, suggesting that a fine tuning of auxin levels is required for optimal nodule development. Also, it has been shown that isoflavonoids can act as inhibitors of auxin transport, modulating the relative hormone levels at the site of cell differentiation (Subramanian et al. 2006; Wasson et al. 2006).

During the past years, several studies were carried out on the model legumes M. truncatula and Lotus japonicus, in which expression profiles of nodulating and non-nodulating roots were 
compared in order to identify genes induced during nodule formation (Asamizu et al. 2005; Barnett et al. 2004; Colebatch et al. 2004; Lohar et al. 2006; Tesfaye et al. 2006). Similar studies have been conducted at the protein level using proteomics (Bestel-Corre et al. 2004; Larrainzar et al. 2007; Rolfe et al. 2003; Wan et al. 2005). Many genes whose transcript or protein levels are modulated during the legume-rhizobium interaction have crucial roles in nodule formation process. These are mainly genes activated downstream of host receptors upon NF perception (Stacey et al. 2006). However, very little is known about plant genes responsible for rhizobium strain-specific recognition that led to a competitive and efficient nodulation. In agronomical systems, highly efficient strains used as inoculants are poor competitors and nodules mainly are occupied by strains of rhizobia naturally present in the soil (Dowling and Broughton 1986; Thies et al. 1991). For this reason, understanding the molecular basis of competitiveness is of vital importance to improve nitrogen fixation in legume crops of major human nutrition significance, such as the common bean.

Common bean (Phaseolus vulgaris) is one of the most ancient crops in America, and genetic diversification into two major centers was proposed: the Mesoamerican center (Mexico, Central America, and Colombia) and the Andean center in South America (Ecuador, Peru, and Argentina) (Gepts 1998). Among the rhizobia recognized as microsymbionts of $P$. vulgaris, Rhizobium etli bv. phaseoli is the predominant species found associated with common bean from Mexico, Colombia, and South Andes (Amarger 2001). In a previous work, we have shown hostdependant competitiveness in the interaction between common bean and $R$. etli (Aguilar et al. 2004). In an attempt to identify genes from the plant involved in this preferential selection of $R$. etli strains, an analysis based on suppressive subtractive hybridization (SSH) was performed. A total of 41 independent bean
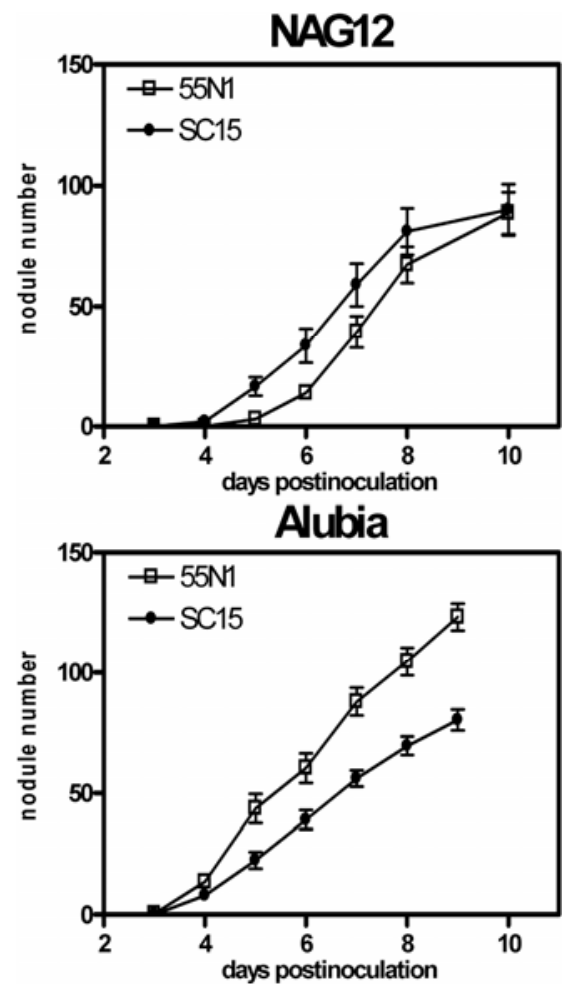

Fig. 1. Time-course nodulation response of Mesoamerican and Andean Phaseolus vulgaris cultivars upon inoculation with Rhizobium etli SC15 or $55 \mathrm{~N} 1$. Number of nodules formed with either $R$. etli strain SC15 or $55 \mathrm{~N} 1$ in bean roots of the Mesoamerican cv. NAG12 (upper panel) or the Andean cv. Alubia (lower panel) at the indicated days postinoculation. Results are means $(n=10) \pm$ standard deviation. tentative consensus sequences (TCs) differentially expressed in response to two $R$. etli strains of varying nodulation efficiency was obtained. Nine of them were confirmed to differentially accumulate in more efficient interactions. The expression pattern of selected cDNAs also was investigated in an Andean host upon inoculation with both $R$. etli strains.

\section{RESULTS}

Nodulation response of $P$. vulgaris upon inoculation with $R$. etli genotype nodC $\alpha$ (strain SC15) and nodC $\delta$ (strain 55N1).

Results from our previous work using co-inoculation experiments suggested that the host is the determinant in the preference of $R$. etli strains (Aguilar et al. 2004). This preference was associated with polymorphism in the nod $\mathrm{C}$ gene, which encodes for an $\mathrm{N}$-acetyl-glucosaminyltransferase involved in the first step of NF assembly. The Mesoamerican bean cv. Negro Xamapa was almost exclusively nodulated by $R$. etli strains carrying the nodC allele type $\alpha$, whereas nodules formed in an Andean cultivar were occupied largely by $R$. etli strains carrying the nod $\mathrm{C}$ allele type $\delta$. To evaluate whether efficiency in nodulation differs between certain host-R. etli strain combinations, the number, size, and shape of nodules formed in the Mesoamerican and Andean cultivars upon inoculation with both bacterial genotypes were monitored at different times after inoculation. Although nodules formed in both cases were comparable in size and shape (data not shown), a significant difference in the number of nodules was observed when bean plants from the two centers of bean domestication were inoculated with $R$. etli strains carrying allele nodC type $\alpha$ or $\delta$ (Fig. 1). The Mesoamerican cv. NAG12, which shares genetic background with Negro Xamapa, presented a significantly higher number of nodules between 4 and 8 days postinoculation (dpi) when inoculated with SC15 than when inoculated with strain 55N1. SC15 is an $R$. etli strain carrying the allele nodC type $\alpha$ that is found predominantly among isolates from the Mesoamerican regions, whereas $55 \mathrm{~N} 1$ strain carries the allele nod $\mathrm{C}$ type $\delta$ that is found predominantly in the Andean populations (Aguilar et al. 2004). Similar results were obtained with cv. Negro Xamapa (data not shown). Because this work has been performed with these two rhizobial genotypes, hereafter we will refer to both genotypes nodC type $\alpha$ and nod $\mathrm{C}$ type $\delta$ of $R$. etli as SC15 and 55N1. In contrast to that observed in NAG12, 55N1 produced more nodules than SC15 when Alubia, a genotype with an Andean genetic background (Gepts 1998), was used in a similar experiment, indicating that bean plants are nodulated earlier by strains from the same geographic origin.

\section{Identification of cDNAs differentially accumulated in root hairs of $P$. vulgaris Negro Xamapa inoculated with $R$. etli $\mathrm{SC15}$ versus $55 \mathrm{~N} 1$.}

In order to gain insight into the transcriptional events that take place in the early stages of the specific and highly efficient nodulation of common bean triggered by the recognition of particular lineages of $R$. etli, an SSH approach was used. Since nodules were detected approximately 4 dpi (Fig. 1), we assumed that, in root hairs harvested $24 \mathrm{~h}$ postinoculation (hpi), early plant response to the presence of rhizobia already has taken place, and therefore, the hairs are suitable for detection of early expressed genes. cDNA from root hairs of the Mesoamerican cv. Negro Xamapa harvested 24 hpi with SC15 (tester) was subtracted with cDNA from root hairs 24 hpi with $55 \mathrm{~N} 1$ (driver). Clones obtained after subtraction were sequenced from both ends, giving, in all, 218 sequences that were assembled into 41 TCs and named Pv-RHS24-01 to -41 for $P$. vulgaris root hairs subtraction at $24 \mathrm{~h}$ (Table 1). The comparison 
of TCs against The Institute for Genomic Research Phaseolus vulgaris Gene Index (TIGR PhvGI, release 1.0) using BLASTN showed that 32 TCs matched sequences in the database, whereas the remaining 9 TCs represented newly discovered common bean genes, which included Pv-RHS24-01, PvRHS24-04, Pv-RHS24-13, Pv-RHS24-17, Pv-RHS24-19, PvRHS24-33, Pv-RHS24-34, Pv-RHS24-39, and Pv-RHS24-40. In order to assign putative functions to the cDNAs, consensus sequences of resulting TCs were compared with the GenBank nonredundant (nr) database using BLASTX (Table 1). Highest BLASTX scores were used to group the TCs into functional categories (Fig. 2). Of the TCs, 39 (95\%) showed similarity to protein sequences deposited in the $\mathrm{nr}$ database. Among them, 34 TCs showed similarities to protein with an assigned putative function, whereas only 5 were found to encode for putative proteins of unknown functions. The identified genes encoded for proteins within several functional categories, including protein synthesis and processing $(20 \%)$, primary metabolism (15\%), signal transduction (12\%), transport (10\%), redox and stress $(7 \%)$, secondary and hormone metabolism $(7 \%)$, and gene expression and RNA metabolism (5\%).

\section{Validation of differential expression on selected SSH clones by qRT-PCR.}

A subset of genes from the SSH results was selected for validation by quantitative reverse-transcriptase polymerase chain reaction (qRT-PCR) analysis. The selected genes encoded proteins with putative functions in signal transduction, namely Pv-RHS24-01 (a putative receptor-like kinase), Pv-RHS24-03 (a small GTP binding protein Rab11c) and Pv-RHS24-13 (a nucleotide binding site leucine-rich repeat [NBS-LRR]-type protein). Pv-RHS24-02 and Pv-RHS24-07, an auxin downregulated gene and an isoflavone reductase gene, respectively, are members of secondary and hormone metabolism category, whereas Pv-RHS24-27, a CCAAT binding factor subunit C, belongs to the gene expression and RNA processing category. In addition, representative members of the remaining categories also were selected for validation, such as GAPDH $\left(\mathrm{Pv}^{-}\right.$ RHS24-15), lipoxygenase (Pv-RHS24-08), an aquaporine (PvRHS24-29), a PRL1 interacting protein (Pv-RHS24-34), and a protein of unknown function (Pv-RHS24-28). Inclusion of a previously characterized common bean lipoxygenase (Porta and Rocha-Sosa 2000) was used as a comparison with results obtained in this work.

Expression of selected genes was assessed by qRT-PCR in bean roots inoculated with $R$. etli strain SC15 or $55 \mathrm{~N} 1$. qRTPCR results supported the differential behavior expected in 9 of 11 tested genes, in which transcript levels were found to be higher in roots inoculated with $R$. etli strain SC15 than those inoculated with strain 55N1 or mock-inoculated (control) (Fig. 3). Two genes, Pv-RHS24-29 and Pv-RHS24-34, presented similar mRNA levels in SC15- and 55N1-inoculated roots, but higher than in control plants (data not shown). Transcripts of Pv-RHS24-02 and Pv-RHS24-27 showed the highest differences

Table 1. cDNAs differentially induced in Phaseolus vulgaris root hairs by SC15 versus 55N1 identified by suppressive subtractive hybridization

\begin{tabular}{|c|c|c|c|}
\hline Tentative contig & Best nonredundant database match & BLASTX E-value & No. of sequences \\
\hline Pv-RHS24-01 & Serine/threonine protein kinase, Oryza sativa & $8 \mathrm{e}^{-73}$ & 8 \\
\hline Pv-RHS24-02 & ARG10 auxin down-regulated, Vigna radiata & $4 \mathrm{e}^{-115}$ & 31 \\
\hline Pv-RHS24-03 & RAB11C, Lotus japonicus & $3 \mathrm{e}^{-100}$ & 25 \\
\hline PV-RHS24-04 & Unknown protein, Oryza sativa & $8 \mathrm{e}^{-58}$ & 11 \\
\hline Pv-RHS24-05 & ATP synthase alpha/beta, Glycine $\max$ & $4 \mathrm{e}^{-154}$ & 10 \\
\hline Pv-RHS24-06 & Protein phosphatase 1 catalytic beta subunit, Medicago sativa & $2 \mathrm{e}^{-162}$ & 8 \\
\hline Pv-RHS24-07 & isoflavone reductase homolog 1, Glycine max & $6 \mathrm{e}^{-94}$ & 8 \\
\hline Pv-RHS24-08 & Lipoxygenase, Sesbania rostrata & $6 \mathrm{e}^{-139}$ & 8 \\
\hline Pv-RHS24-09 & Unknown protein, Arabidopsis thaliana & $3 \mathrm{e}^{-44}$ & 8 \\
\hline Pv-RHS24-10 & No significant hits & & 7 \\
\hline Pv-RHS24-11 & Ribosomal_S8e, Oryza sativa & $9 \mathrm{e}^{-40}$ & 7 \\
\hline Pv-RHS24-12 & Putative TCP-1/cpn60 chaperonin, Oryza sativa & $1 \mathrm{e}^{-120}$ & 6 \\
\hline Pv-RHS24-13 & Nucleotide binding site leucine-rich repeat-type disease resistance protein, Glycine max & $2 \mathrm{e}^{-127}$ & 6 \\
\hline Pv-RHS24-14 & Arf GTPase activating protein, Medicago truncatula & $1 \mathrm{e}^{-21}$ & 6 \\
\hline Pv-RHS24-15 & Glyceraldehyde-3-phosphate dehydrogenase, Glycine max & $1 \mathrm{e}^{-150}$ & 6 \\
\hline Pv-RHS24-16 & Monodehydroascorbate reductase, Pisum sativum & $1 \mathrm{e}^{-73}$ & 6 \\
\hline Pv-RHS24-17 & Protein transporter, Arabidopsis thaliana & $6 \mathrm{e}^{-48}$ & 5 \\
\hline Pv-RHS24-18 & Histone H2A-like protein, Arabidopsis thaliana & $5 \mathrm{e}^{-38}$ & 5 \\
\hline Pv-RHS24-19 & ATP binding / protein binding, Arabidopsis thaliana & $7 \mathrm{e}^{-115}$ & 5 \\
\hline Pv-RHS24-20 & Antiporter/triose-phosphate transporter, Arabidopsis thaliana & $4 \mathrm{e}^{-100}$ & 5 \\
\hline Pv-RHS24-21 & Unknown protein, Oryza sativa & $3 \mathrm{e}^{-29}$ & 4 \\
\hline Pv-RHS24-22 & Organic anion transporter, Arabidopsis thaliana & $2 \mathrm{e}^{-100}$ & 4 \\
\hline Pv-RHS24-23 & 40 S ribosomal protein 55 , Cicer arietinum & $7 \mathrm{e}^{-66}$ & 4 \\
\hline Pv-RHS24-24 & Copine III-like, Oryza sativa & $2 \mathrm{e}^{-69}$ & 3 \\
\hline Pv-RHS24-25 & Peptidyl-prolyl cis-trans isomerase, Arabidopsis thaliana & $7 e^{-94}$ & 3 \\
\hline Pv-RHS24-26 & Protease inhibitor, Sesbania rostrata & $1 \mathrm{e}^{-75}$ & 2 \\
\hline Pv-RHS24-27 & CCAAT-binding factor, subunit $\mathrm{C}$, Medicago truncatula & $1 \mathrm{e}^{-128}$ & 2 \\
\hline Pv-RHS24-28 & Unknown protein, Oryza sativa & $4 \mathrm{e}^{-13}$ & 2 \\
\hline Pv-RHS24-29 & Plasma membrane aquaporin, Vitis vinifera & $1 \mathrm{e}^{-108}$ & 2 \\
\hline Pv-RHS24-30 & Asparagine synthetase type II, Phaseolus vulgaris & 0.0 & 2 \\
\hline Pv-RHS24-31 & Diaminopimelate decarboxylase, Arabidopsis thaliana & $6 \mathrm{e}^{-44}$ & 2 \\
\hline Pv-RHS24-32 & Hypothetical protein, Trifolium pratense & $2 \mathrm{e}^{-146}$ & 2 \\
\hline Pv-RHS24-33 & Bacterial IS-element, Arabidopsis thaliana & $1 \mathrm{e}^{-155}$ & 1 \\
\hline Pv-RHS24-34 & PRLI-interacting factor G-like protein, Oryza sativa & $1 \mathrm{e}^{-07}$ & 1 \\
\hline Pv-RHS24-35 & Ribosomal protein small subunit 28 , Helianthus annuus & $1 \mathrm{e}^{-19}$ & 1 \\
\hline Pv-RHS24-36 & Aldehyde dehydrogenase (NAD+), Nicotiana tabacum & $6 \mathrm{e}^{-100}$ & 1 \\
\hline Pv-RHS24-37 & Hydrolase/phosphoglycolate phosphatase, Arabidopsis thaliana & $2 \mathrm{e}^{-27}$ & 1 \\
\hline Pv-RHS24-38 & S-adenosylmethionine synthetase, Phaseolus lunatus & 0 & 2 \\
\hline Pv-RHS24-39 & Splicing factor-like protein, Vitis riparia & $1 \mathrm{e}^{-36}$ & 1 \\
\hline Pv-RHS24-40 & No significant hits & & 1 \\
\hline Pv-RHS24-41 & LEDI-5c protein, Lithospermum erythrorhizon & $1 \mathrm{e}^{-57}$ & 1 \\
\hline
\end{tabular}


(fourfold higher) in roots inoculated with SC15 compared with those inoculated with the strain 55N1. Pv-RHS24-08 and PvRHS24-13 presented expression ratios that were above threefold. Expression ratios for the remaining genes ranged from 1.6to 2.3 -fold. These results indicate that the one host exhibits differential gene induction in response to two rhizobium lineages which are closely related to each other.

Expression analysis of selected SSH clones in plant organs.

In order to further study the expression pattern of the identified SSH genes, qRT-PCR analysis was performed on RNA obtained from different common bean tissues (Fig. 4). Expression of three of the selected genes, namely Pv-RHS24-01, PvRHS24-07, and Pv-RHS24-08, was found to be quite specific of root compared with stem or leaf, whereas the others were expressed in all the tissues examined (e.g., Pv-RHS24-03, PvRHS24-27, and Pv-RHS24-28). In addition, a similar comparison was performed between young ( $7 \mathrm{dpi}$ ) and mature (14 dpi) nodules from the Mesoamerican cv. Negro Xamapa induced by either SC15 or $55 \mathrm{~N} 1$ (Fig. 4). Transcripts for all tested genes were found to accumulate at significantly higher levels in nodules of 7 dpi with strain SC15 than in those colonized by strain $55 \mathrm{~N} 1$, and this is in agreement with the patterns observed at $24 \mathrm{hpi}$. The same trend continued in nodules of $14 \mathrm{dpi}$ for Pv-RHS24-01, Pv-RHS24-03, Pv-RHS24-13, and Pv-RHS2427. It is interesting to note that transcripts of Pv-RHS24-07 and PV-RHS24-08 were consistently less abundant in nodules of 7 or 14 dpi than in noninoculated roots.

\section{Time-course response of two differential genes.}

The symbiotic interaction is an ordered and sequential process which involves complex responses. Therefore, to further characterize mRNA accumulation in response to $R$. etli strains, two selected SSH clones were analyzed through a time course. The two clones examined, Pv-RHS24-03 and Pv-RHS24-27, were chosen because they are good candidates to participate in signal transduction and gene activation. The analysis was performed in more detail during the first 48 hpi with either strain SC15 or $55 \mathrm{~N} 1$ (Fig. 5). Although both genes showed a similar direction of change at each of the time points evaluated in response to both rhizobia strains, transcripts were, in general, found to have accumulated higher in roots challenged with $R$. etli strain
SC15 than with strain $55 \mathrm{~N} 1$ at all the time points examined. Transcript levels of Pv-RHS24-03 and Pv-RHS24-27 accumulated as early as $3 \mathrm{hpi}$, reached a maximum at $12 \mathrm{hpi}$ (with expression ratios to noninoculated roots at 5- and 11-fold for $\mathrm{Pv}$ RHS24-03 and Pv-RHS24-27, respectively), and then decreased. This result indicates that, in the host response to each $R$. etli strain, difference in expression of the two genes we examined is quantitative rather than qualitative.

\section{Differentially expressed genes in an Andean cultivar.}

In order to assess a transcriptional profile in an Andean cultivar, we performed a qRT-PCR analysis using the same two $R$. etli strains described above. Differential expression between Mesoamerican and Andean cultivars can be related either to an intrinsic and specific pattern of response, or to a specific recognition of the $R$. etli strain by the plant. Therefore, we tested the expression pattern of selected SSH genes in a common bean cultivar from the Andean domestication region challenged with 55N1 or SC15. Pv-RHS24-13 and Pv-RHS24-28 showed a slight induction (1.6- to 1.8-fold higher) in response to $55 \mathrm{~N} 1$ relative to control or SC15-inoculated plants (Fig. 6). The other TCs tested, Pv-RHS24-01, Pv-RHS24-03, PvRHS24-07, and Pv-RHS24-27, showed no significant changes in their transcript levels. These results taken together indicate that hosts from different domestication centers have differential responses to rhizobial infection that are strain dependent.

\section{DISCUSSION}

Previously, we have reported the existence of strong sympatric competition effects that demonstrated nodulation preference between lineages of $R$. etli and bean from the same region (Aguilar et al. 2004). The search for the host traits which may be involved in this strain preference is one of the goals pursued in this work. Our current state of knowledge regarding the symbiotic interaction between legumes and rhizobia recognizes significant progress in the identification of key molecules that are involved in the initial signaling between host and bacterium and the consequent signal transduction pathways. Genes essential for NF perception or for transduction components of the pathway triggered by NF, which lead to activation of early nodulin genes, have been identified in the model leg-

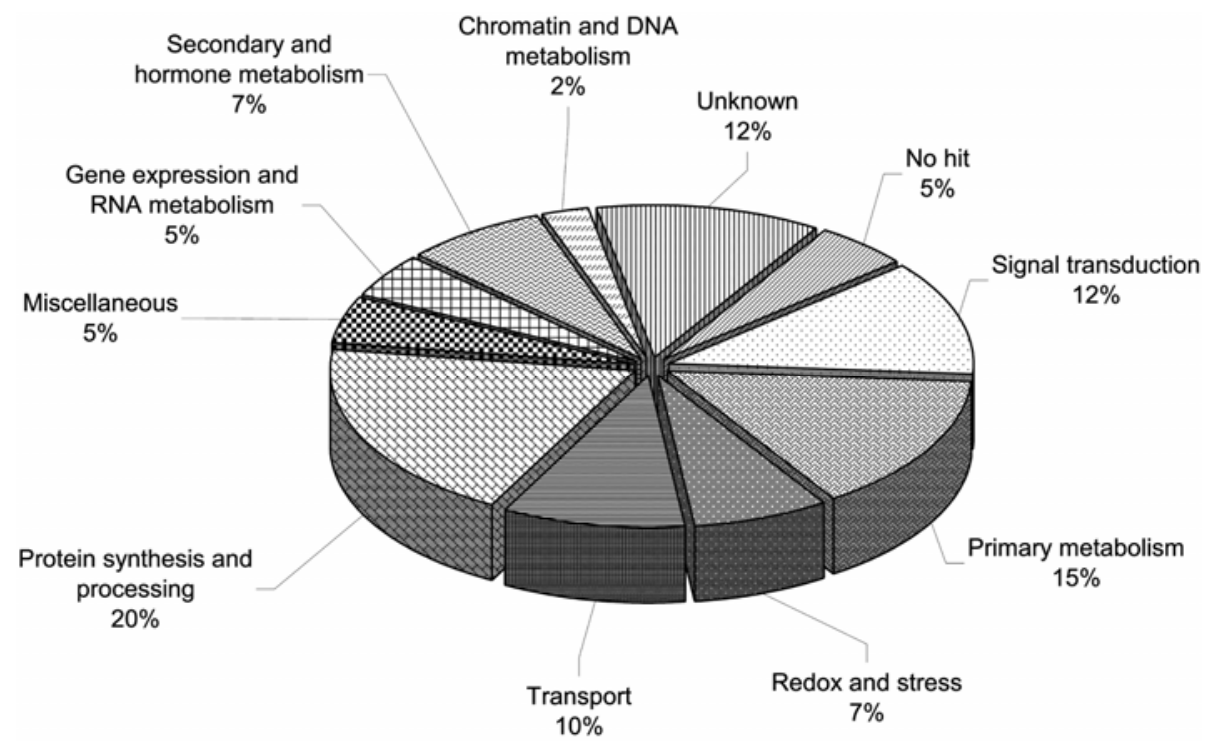

Fig. 2. Functional clustering of Phaseolus vulgaris cDNAs differentially accumulated in root hairs by SC15 versus 55N1. Distribution of $P$. vulgaris cDNAs identified by suppressive subtractive hybridization into functional categories according to their best BLASTX hits. Percentages were calculated with the total number of tentative consensus sequences. 
umes L. japonicus and M. truncatula (Oldroyd et al. 2005; Stacey et al. 2006). However, our knowledge of host genes other than those involved in these preinfection signaling events, which may be involved in response to other rhizobial components, is rather limited and has not been fully examined. The host nodulation pathway activated in response to closely related rhizobial strains is expected to be similar. Differences in this response can account for the nodulation preference between symbiotic partners that have coevolved in the same geographic region to allow the nodulation process to be more efficient.

Although a significant contribution to genomics resources for $P$. vulgaris recently has been made by Ramírez and associates (2005) and Melotto and associates (2005) through sequencing and analysis of expressed sequence tags (EST), the availability of genomic sequences and platforms for whole-genome gene expression analysis are still quite limited. Taking this into consideration, we approached the identification of common bean genes by applying an SSH strategy, which has proven to be useful for retrieving sequences differentially represented between samples treated with two lineages of $R$. etli. This method was successful in identifying diverse genes in other legume plants such as M. truncatula (Godiard et al. 2007; Sánchez et al. 2005). Common bean roots show microscopic visible deformation and curling of root hairs upon contact with its microsymbiont (Taté et al. 1994). In this study, root hairs were selected as the biological sample for the subtraction because it is where cellular changes are triggered upon contact with bacteria, and, therefore, allow detection of differentially accumulated mRNAs. A potential aspect of this analysis that should be taken into consideration is that genes downregulated by infection of strain SC15 or upregulated by infection of strain $55 \mathrm{~N} 1$ are not represented in the library we examined.

Analysis of the sequences obtained revealed 41 SSH independent clones from a library of presumed common bean genes that are upregulated in the early stage of root interaction with one of the two $R$. etli strains. These $41 \mathrm{SSH}$ clones represent genes encoding for products with diverse functions. Because it is expected that bean plants inoculated with one or the other strain of $R$. etli induce genes that are common to both interactions, clones obtained from the subtraction will represent enriched cDNA populations that correspond to genes involved in specific strain recognition, as well as differential strain-depend-
Pv-RHS24-01

(Ser/Thr protein kinase)

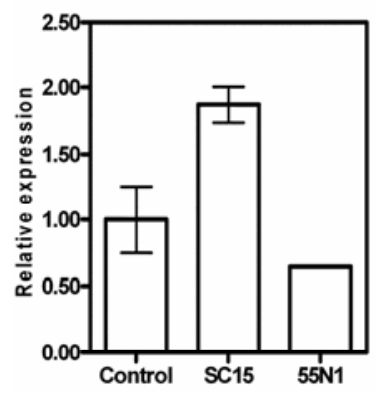

Pv-RHS24-07

(Isoflavone reductase)

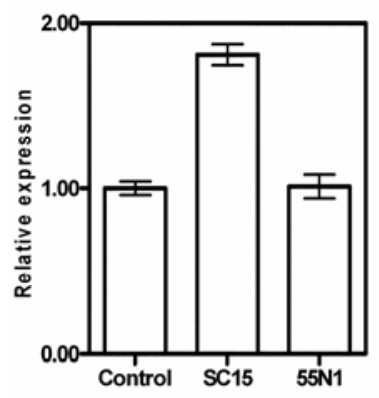

Pv-RHS24-15

(GAPDH)

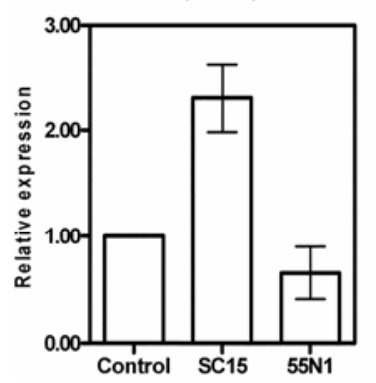

Pv-RHS24-02

(ARG10 auxin down-regulated)

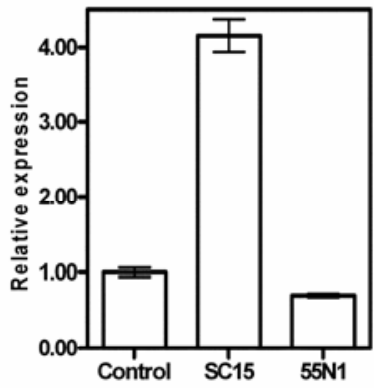

Pv-RHS24-08

(Lipoxygenase)

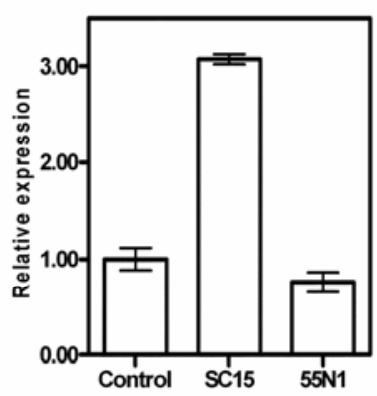

Pv-RHS24-27

(CCAAT-binding factor, subunit C)

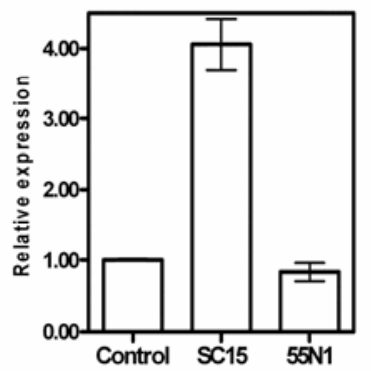

Pv-RHS24-03

(RAB11C)

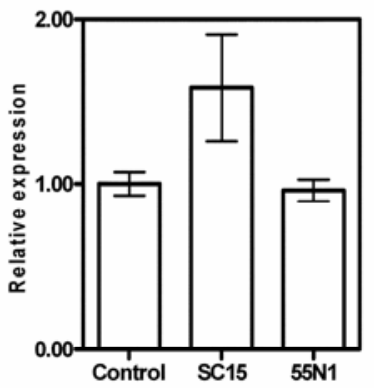

Pv-RHS24-13

(NBS-LRR type protein)

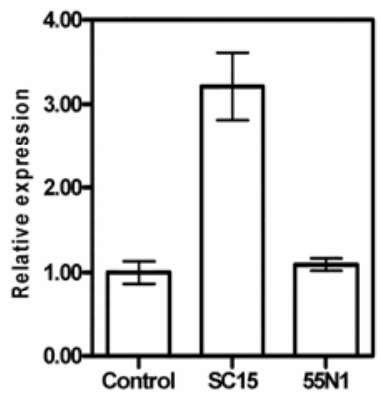

Pv-RHS24-28

(Unknown protein)

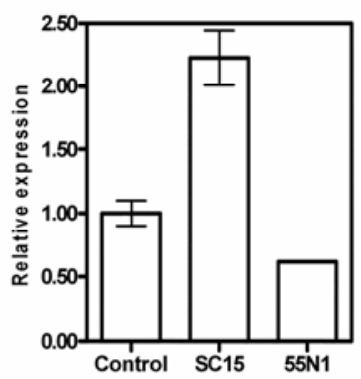

Fig. 3. Quantitative reverse-transcriptase polymerase chain reaction analysis of selected cDNAs identified as differentially expressed by subtractive hybridization approach. RNA from Phaseolus vulgaris roots (Mesoamerican cv. Negro Xamapa) inoculated for $24 \mathrm{~h}$ with yeast extract-manitol medium (control) or Rhizobium etli SC15 or 55N1 was used. Transcript levels were normalized to elongation factor $1 \alpha$ values and presented as relative to the control sample. Means \pm standard deviation of three technical replicates are presented. Results are representative of three independent biological samples. 
ent response. In addition, genes induced to higher levels in SC15-treated root hairs as a consequence of this signaling also would be detected as differentially expressed by this approach, as is the case for Pv-RHS24-03 and Pv-RHS24-27 (Fig. 5). The set of genes identified here represents useful data to provide new insights into which differential responses at very early stages of the infection are involved in preferential nodulation. No genes encoding proteins related to known nodulins were found in our collection. However, a large proportion of the SSH clones were found to be related to proteins involved in protein synthesis and

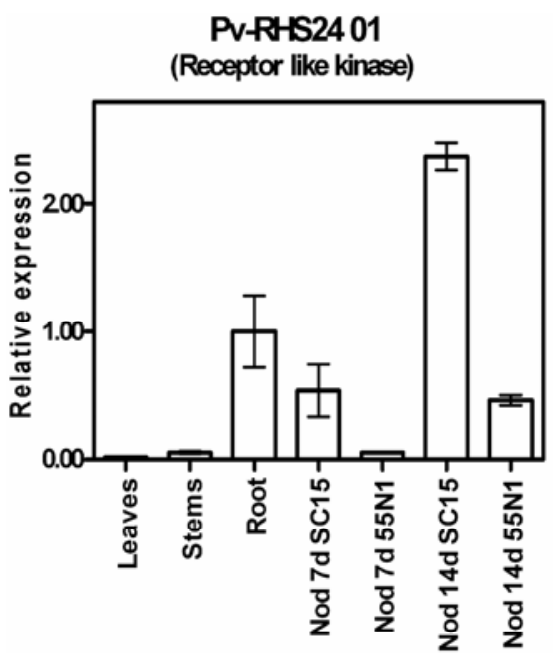

Pv-RHS24 07

(Isoflavone reductase)

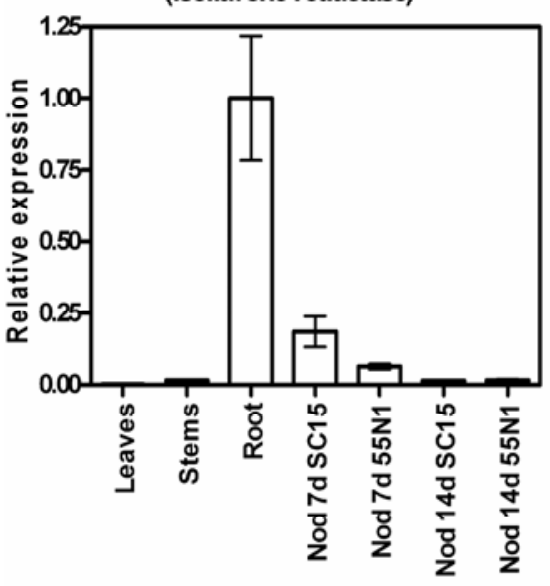

Pv-RHS24 27

(CCAAT binding factor, subunit C)

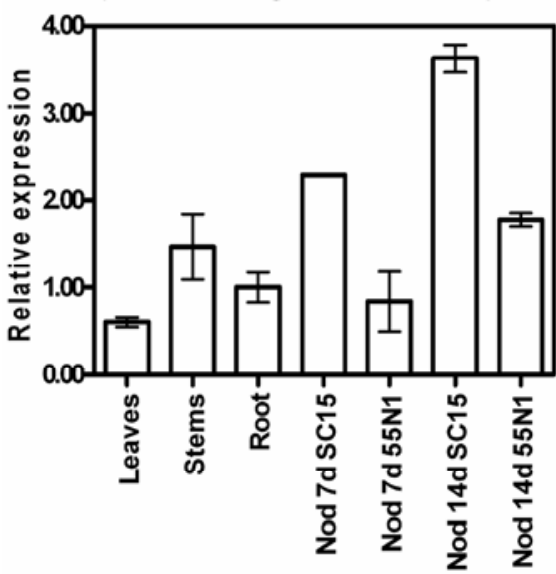

Pv-RHS2402

(ARG10 auxin down-regulated)

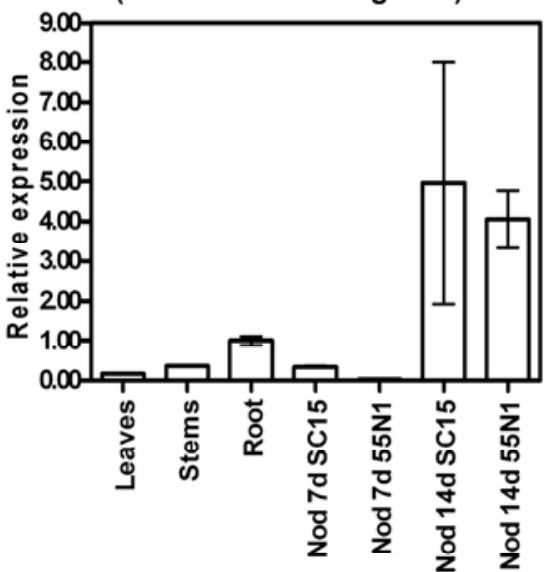

Pv-RHS24 08

(Lipoxygenase)

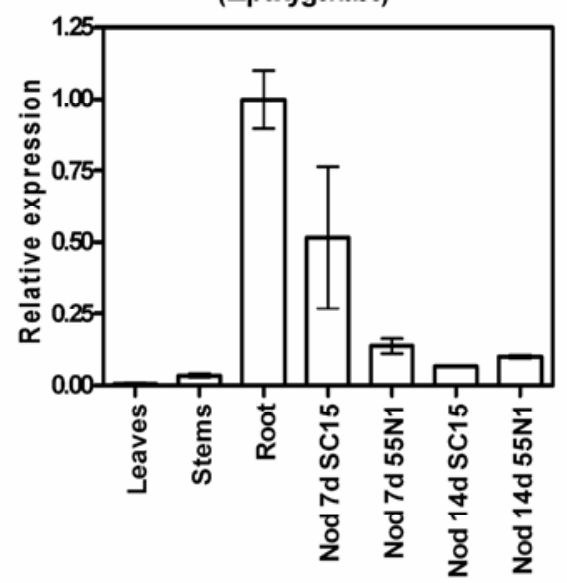

Pv-RHS24 28

(Unknown protein)

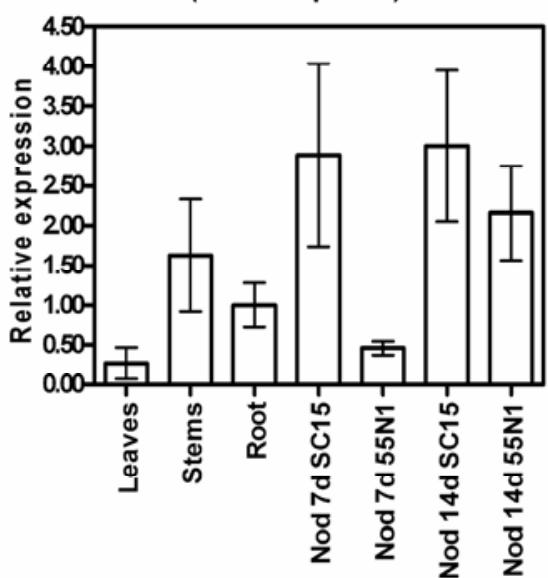

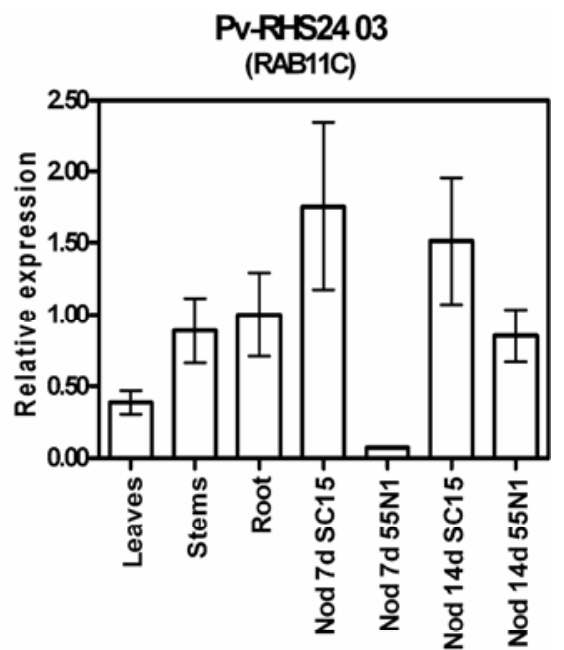

Pv-RHS24 13

(NBS-LRR type protein)

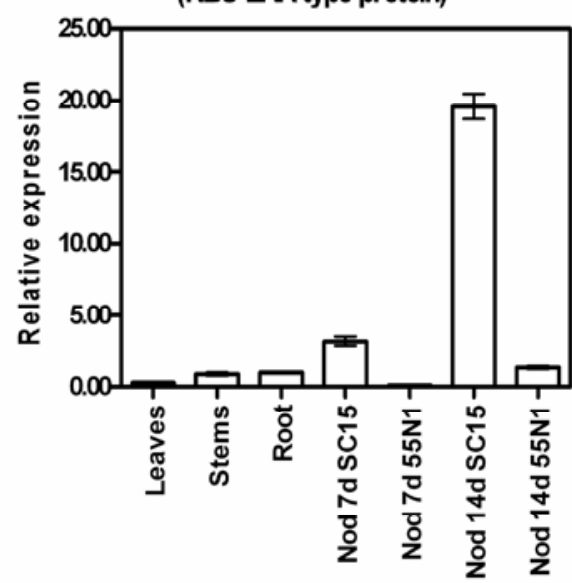

Fig. 4. Relative transcript levels obtained by quantitative reverse-transcriptase polymerase chain reaction of selected cDNAs in different organs of the Mesoamerican cv. Negro Xamapa: leaves, stems, roots, and nodules at 7 days postinoculation (dpi) with Rhizobium etli SC15 (Nod 7d SC15) or 55N1 (Nod 7d 55N1) and nodules at 14 dpi with $R$. etli SC15 (Nod 14d SC15) or 55N1 (Nod 14d 55N1). Transcript levels were normalized to elongation factor $1 \alpha$ values and presented as relative to the root sample. Means \pm standard deviation of three technical replicates are presented. Results are representative of two biological replicates. 
processing, primary metabolism, and signal transduction. We biased our analysis to those genes grouped in the signal transduction category, bearing in mind that our initial hypothesis is that the preferential rhizobial nodulation should involve recognition and activation of specific pathways induced by the cognate strain. Analysis of SSH libraries cannot be conclusive in terms of the differential levels of mRNA; therefore, data was validated further by the use of qRT-PCR, showing that most of the genes followed the expected expression pattern, with higher values in the more efficient interaction (Fig. 3).

Two of the identified genes, Pv-RHS24-01 and Pv-RHS24-13, show high homology to previously characterized plant receptors (Table 1). Plants have a sophisticated array of receptors that can, directly or indirectly, recognize the presence of nonhost microorganisms, pathogens, and symbionts. Pv-RHS24-01 contains a protein kinase domain similar to the intracellular domain of the protein kinase-like receptor NP_195827 of Arabidopsis thaliana and with no matches in the TIGR PhvGI database. Pv-RHS2413 is homologous to Rpgl-b from soybean (Ashfield et al. 2004), which belongs to the very well characterized non-toll interleukin 1 receptor-NBS-LRR proteins, typically linked to pathogen resistance. Similarly to Pv-RHS24-01, the Pv-RHS2413 sequence did not show any match when blasted against the TIGR PhvGI database. Genes encoding NBS-LRR proteins have been identified and found to be induced in other host-rhizobia as well as host-pathogen interactions (Colebatch et al. 2004; Manthey et al. 2004; Samac and Graham 2007; Tesfaye et al. 2006; Yahyaoui et al. 2004). Binding of effector molecules leads to conformational changes of the receptor, promoting the hydrolysis of ATP at the NBS domain, and eventually leading to uncharacterized downstream signaling. Although NBS-LRR proteins typically have been associated with recognition of pathogens in plant and animal systems, it is tempting to speculate that different members of the gene family also can participate in the suppression of defense responses upon recognition of symbiotic partners.

Another upregulated SSH clone, Pv-RHS24-03, corresponds to a previously annotated common bean gene encoding Rab11c, a member of the large family of small GTP-binding protein. Members of this protein family also have been detected in mature nodules of soybean and L. japonicus (Borg et al. 1997; Cheon et al. 1993). Rab proteins play important roles in cellular processes such as polar growth via regulating intracellular membrane trafficking, cellular division, and nuclear import (Song et al. 2006). Activation of developmental events depends on the GTP bound form of the protein, whereas intrinsic GTPase activity turns off this activation. The GTPase activity can be modulated by GTPase-activating proteins. It is interesting that another TC detected in our analysis, PV-RHS24-14, presents a strong sequence homology with an Arf GTPase-activating protein of M. truncatula. Because expression of Rab11c was activated early after infection, one may speculate that redirectioning of tip growth of the root hair is mediated by this protein. Certainly, further experiments are needed to sustain the hypothesis.

Pv-RHS24-27 encodes a predicted protein homologous to the HAP5, a subunit of the heterotrimeric CCAAT-transcriptional factor. This gene was found to be highly expressed in common bean roots infected with strain SC15 as compared with strain $55 \mathrm{~N} 1$ as early as $3 \mathrm{~h}$ after the onset of the treatment (Fig. 5). HAP5 mRNAs also accumulate in nodules occupied by $\mathrm{SC} 15$ at 7 and $14 \mathrm{dpi}$ at higher levels than in those formed by $55 \mathrm{~N} 1$. The $M$. truncatula MtHAP2-1 gene, which encodes HAP2, another subunit of the CCAAT complex transcriptional factor, is important in nodule development by controlling meristem persistence in the nodule and likely symbiotic rhizobial release from the IT (Combier et al. 2006). Therefore, if regulation of nodulation in common bean makes use of transcription factors that bind CCAAT motif, PV-RHS24-27 could play a role in nodule development in a way similar to that shown for the $M$. truncatula HAP2. In addition, our data indicated PVRHS24-27 to be expressed at early stages after infection and to be sensitive to specific strains in a host-dependent way.

Another of the differentially expressed clones, PV-RHS2407, encodes a putative isoflavone reductase, an enzyme that is part of the biosynthetic pathway of isoflavonoids. Flavonoids and isoflavonoids are exuded from legume roots as early components of the symbiotic interaction and they act as inducers of bacterial nodulation genes. Accumulation of chalcone synthase transcripts was found in roots inoculated with rhizobia or NF (Krause et al. 1997). Similarly, genes of the chalcone metabolism were expressed at higher levels in Sinorhizobium melilotiinoculated roots than in uninoculated roots at early times after infection (Lohar et al. 2006; McKhann et al. 1997). Although PV-RHS24-07 is highly expressed in root compared with shoot tissues and nodules (Fig. 4), our data suggested that the biosynthetic pathway of flavonoids in common bean roots is differentially activated by specific $R$. etli lineages at early stages (24 hpi) of the interaction (Fig. 3), which can lead to an earlier synthesis of NF compared with other strains, and therefore provide competitiveness. Also, a role for isoflavonoids in the division of cortical cells acting as inhibitors of the auxin transport recently was demonstrated (Subramanian et al. 2006; Wasson et al. 2006). Interestingly, PV-RHS24-02 is predicted to encode a protein of unknown function that is downregulated
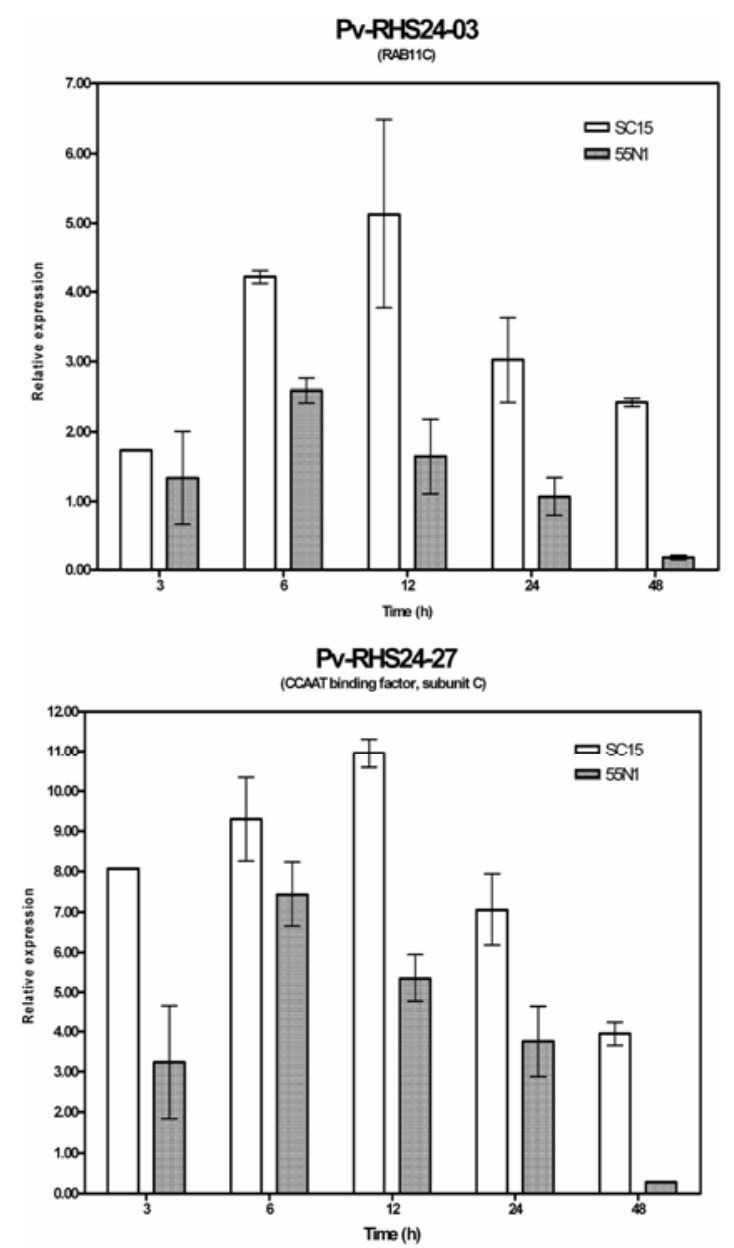

Fig. 5. Time-course transcript levels accumulation of Pv-RHS24-03 (RAB11C) and Pv-RHS24-27 (CCAAT binding factor, subunit C) in Phaseolus vulgaris roots inoculated with Rhizobium etli SC15 or $55 \mathrm{~N} 1$. Transcript levels were normalized to elongation factor $1 \alpha$. Values are means \pm standard deviation of three technical replicates. 

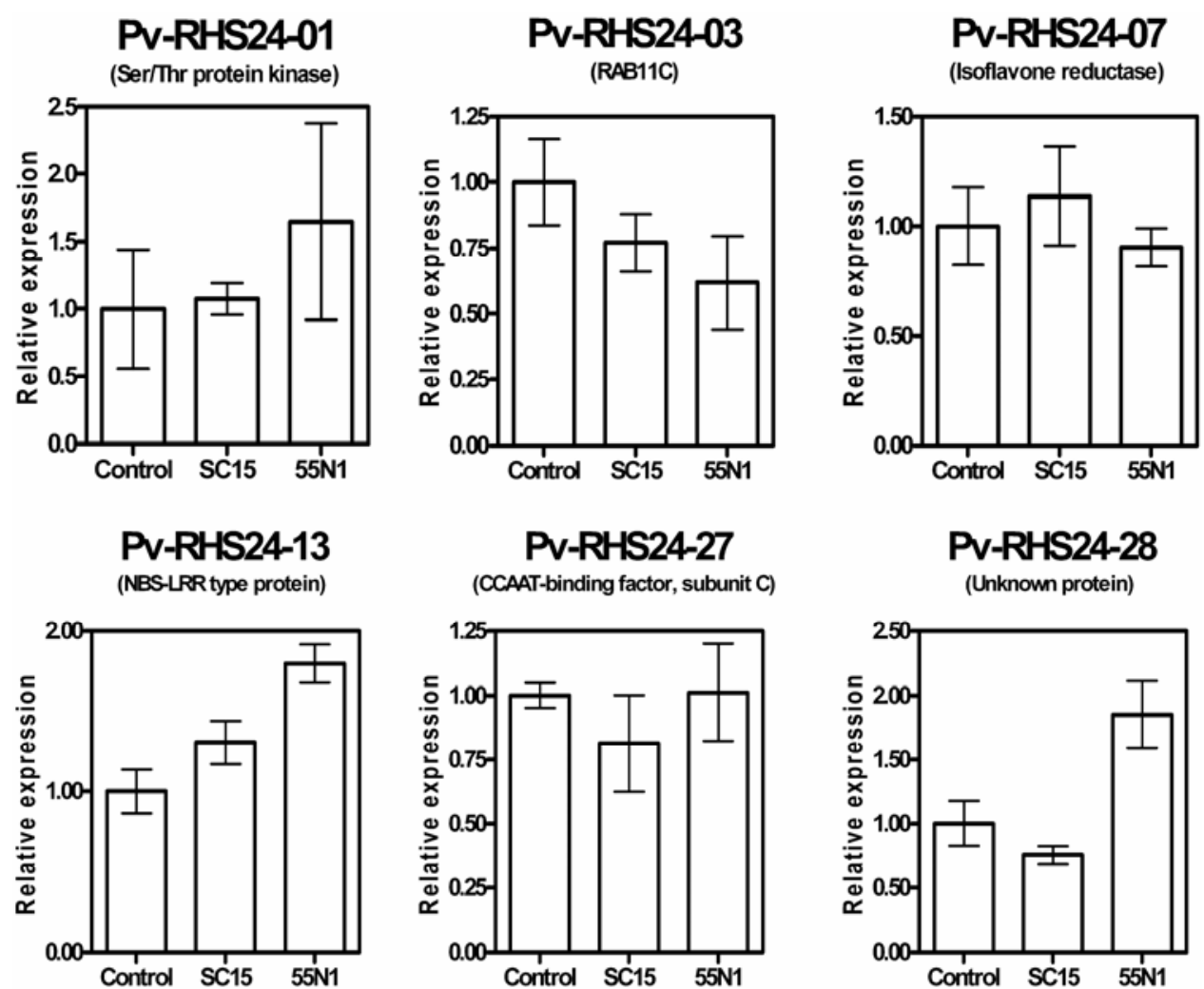

Fig. 6. Quantitative reverse-transcriptase polymerase chain reaction analysis of selected cDNAs in the Andean cv. Alubia. RNA from Phaseolus vulgaris roots inoculated for $24 \mathrm{~h}$ with yeast extract-manitol medium (control) or Rhizobium etli SC15 or 55N1 was used. Transcript levels were normalized to elongation factor $1 \alpha$ values and presented as relative to the control sample. Means \pm standard deviation of three technical replicates are presented. Results are representative of three independent biological samples.

in response to auxin treatment (Hashimoto and Yamamoto 1998) and is highly induced in mature nodules (Fig. 4). Two homologs of auxin downregulated genes also were reported in M. truncatula as highly induced in nodules 10 dpi with $S$. meliloti (Yahyaoui et al. 2004).

Genes differentially expressed in the Mesoamerican cultivar are expected to be related to the recognition or the specific response to the different strains used in this study; however, they also can simply reflect genes which are induced at earlier time points or at higher levels. It also is possible that constitutively expressed genes can be required for the strain-specific recognition by the host, but these genes would not be revealed by the SSH strategy used in this study. qRT-PCR analysis showed that the induction of the $\mathrm{SSH}$ clones responded in a different way when an Andean cultivar was inoculated with $\mathrm{SC} 15$ or $55 \mathrm{~N} 1$ (Fig. 6). Only two of six clones showed increased levels of mRNA in response to $55 \mathrm{~N} 1$, the strain that produced a higher number of nodules in Alubia (Fig. 1). For the other clones analyzed, no significant differences were observed between the two strains, indicating that the response was specific to the Mesoamerican host and not a consequence of an earlier nodulation process. On the other hand, polymorphisms of these genes also can explain differential responses related to strain specificity and, in this case, an induction in both bean cultivars should be expected after inoculation with the $R$. etli strain from the same geographic region.

The distinguishing feature of this work is that the applied strategy identified genes differentially expressed in response to infection with a more competitive strain of the microsymbiont $R$. etli. We were able to significantly enrich our SSH library in genes upregulated by infection with strain $\mathrm{SC} 15$ that were further confirmed by the qRT-PCR. One interesting conclusion drawn from our work is that different strains, grouped within the same species, induce different responses in the same host, albeit both strains are able to induce effective nodulation. It is possible to speculate that some of these genes could contribute to competition and early nodulation in common bean. Certainly, further investigations are needed to confirm the function of these gene products, particularly with genetic studies analyzing gene specific mutants. A transformation method for $P$. vulgaris roots using Agrobacterium rhizogenes recently was reported by Estrada-Navarrete and associates (2006). This advancement will allow a reverse genetic approach to establish roles for candidate genes in the nodulation process. Experiments carried out in our laboratory show that hairy roots recapitulate the phenotypic differences found with wild-type roots, in respect to nodulation with one or the other $R$. etli strain. This allows for phenotypic analysis in the composite plant system (unpublished results). Using this system, genes identified in this study currently are being analyzed using both overexpression and RNAi silencing approaches. In conclusion, our findings support that a set of host genes, other than those specifically involved in the signaling pathway triggered by the interaction between NF and receptor, positively contributes to a more efficient nodulation by a particular rhizobial strain at early stages of infection.

\section{MATERIALS AND METHODS}

Plant and rhizobia material.

Seed of $P$. vulgaris cvs. Negro Xamapa and NAG12 (Mesoamerican) and Alubia Cerrillos (Andean) were provided by G. Hernández (Centro de Ciencias Genómica, Universidad Nacional Autónoma de México, Cuernavaca, Morelos, México) and S. García Medina (Instituto Nacional de Tecnología Agropecuaria, Estación Experimental Agropecuaria Salta, Cerrillos, Argentina). $R$. etli strains SC15 and 55N1 were described pre- 
Table 2. Primers used for quantitative reverse-transcriptase polymerase chain reaction analysis

\begin{tabular}{llll}
\hline Target cDNA & \multicolumn{1}{c}{ Forward primer $\left(\mathbf{5}^{\prime}-\mathbf{3}^{\prime}\right)$} & \multicolumn{1}{c}{ Reverse primer $\left(\mathbf{5}^{\prime}-\mathbf{3}^{\prime}\right)$} & Product size $(\mathbf{b p})$ \\
\hline Pv-RHS24-01 & TTTAACAGGGCACCAGATGATG & CAGCCCAATGCCAGAAATG & 158 \\
Pv-RHS24-02 & AGCCCCTCAAACAAGCAGAAT & CCAAAAACAACCGCCGAAAAG & 174 \\
Pv-RHS24-03 & TGCGAGTGCCTTTTGCTAACA & TTGGCGGAGAGGGAAGTC & 123 \\
Pv-RHS24-07 & AATGCCTTTGCTGGTTACTTCT & GGGGTCATCCACTGCTTTTAT & 159 \\
Pv-RHS24-08 & CCATCAGCTGCATAAGGGTAGT & TCGTTATGCCATGGAGATTAGC & 165 \\
Pv-RHS24-13 & CAGATGGGAAGGAAGGTGGATA & GGGAGATTGGCATGAAGATTGT & 200 \\
Pv-RHS24-15 & GCGAGTGGAGCAAGGCAGTT & GAAGGGTGGCGCTAAGAAGGT & 147 \\
Pv-RHS24-26 & GCTCAGCAGTCTCACCCCTACA & GCTTCTGCTCGCTATGGACTTC & 169 \\
Pv-RHS24-27 & GCAGGGCTATATCGGTCTTTTC & GAGTAACATTTTGGATTCAATG & 103 \\
Pv-EF $1 \alpha$ & AACTACCACCGGCCACTTGAT & AGCACCCAGGCATACTTGAAT & 117 \\
\hline
\end{tabular}

viously (Aguilar et al. 2004). For plant inoculation, rhizobium strains were grown in yeast extract-manitol medium at $28^{\circ} \mathrm{C}$ in an orbital shaker to late exponential phase.

Bean seed were surface sterilized $(30 \mathrm{~s}$ in $100 \%$ [vol/vol] ethanol, transferred to $0.7 \%$ [vol/vol] $\mathrm{NaClO}$ for $15 \mathrm{~min}$, and rinsed six times with sterile water) and germinated on top of $1.5 \%$ (wt/vol) agar plates for 2 days in the dark. Plants were grown hydroponically in Fahraeus media (Fahraeus 1957) in a growth chamber MLR-350HT (Sanyo Electric Co; Osaka, Japan) at $26^{\circ} \mathrm{C}$ in a cycle of $14 \mathrm{~h}$ of day, $10 \mathrm{~h}$ of night for 7 days. Approximately 100 roots were used in each experiment. For rhizobial infection, roots were sprayed with $20 \mathrm{ml}$ of a suspension of Rhizobium etli SC15 or $55 \mathrm{~N} 1$ (absorbance at 600 $\mathrm{nm}$ of approximately 0.8 ). Root hairs were collected $24 \mathrm{hpi}$ as described previously (Bucher et al. 1997; Wan et al. 2005). For qRT-PCR, plants were grown in acrylic boxes ( 17.5 by 23 by $4.5 \mathrm{~cm}$ ) containing Fahraeus media with $1.5 \%$ (wt/vol) agar slopes, in the same conditions described for hydroponic cultures. Two plants per box were grown. Tissues were collected at the indicated time points and immediately frozen in liquid nitrogen for RNA extraction.

\section{Nodulation kinetics.}

Seed were sterilized as described above and pregerminated for 2 days. Germinated seed were transferred to pouches (SCS, Buenos Aires) and incubated in the conditions described above for 7 days. Seedlings then were inoculated with $1 \mathrm{ml}$ of an $R$. etli culture resuspended in Fahraeus medium. Five pouches containing two seedlings each were used per treatment in order to record nodule numbers on a daily-basis.

\section{RNA extraction.}

RNeasy plant mini kit (Qiagen, Valencia CA, U.S.A.) was used to extract RNA for the subtractive hybridization (discussed below). RNA used for qRT-PCR was extracted with TRIZOL (Invitrogen; Carlsbad CA, U.S.A.). Samples were treated with DNAse (Promega Corp., Madison WI, U.S.A.) according to the manufacture's recommendations.

\section{Subtractive hybridization.}

SSH was carried out using the Super SMART PCR cDNA synthesis kit and PCR-Select cDNA subtraction kit (Clontech; BD Biosciences, Palo Alto CA, U.S.A.) according to the instruction manual. For the construction of the subtractive library, tester and driver cDNAs were synthesized using RNA extracted from root hairs of bean plants 24 hpi with $R$. etli strains SC15 and $55 \mathrm{~N} 1$, respectively.

Products of the second nested PCR from subtracted cDNA were cloned into pCR 2.1-TOPO (Invitrogen), which then was transformed into TOP10F' Escherichia coli strain according to the manual instructions. Approximately 300 white and light-blue colonies were picked from petri dishes and regrown overnight in Luria-Bertani medium with ampicillin at $100 \mathrm{mg} / \mathrm{liter}$ in a shaker at $180 \mathrm{rpm}$ and $37^{\circ} \mathrm{C}$. Plasmid DNA was purified by standard procedures (Sambrook et al. 1989) and digested with $E c o$ RI to check for inserted DNA in the plasmid. Presence and size of cloned fragments were examined by PCR using M13 forward and reverse primers according to the TOPO TA Cloning manual. The selected range size was between 350 and $800 \mathrm{bp}$.

\section{Sequence analysis.}

Purified plasmids were sequenced at Macrogen (Seoul, Korea). TCs were obtained using SeqManII from DNAStar package software (DNAStar Inc, Madison WI, U.S.A.) and blasted against TIGR $P$. vulgaris Gene Index using BLASTN (Altschul et al. 1997). Matching sequences were added to the assembly to extend TCs and singletons previously obtained. Resulting consensus sequences then were blasted against GenBank nr database using BLASTX with a cut off value of $\mathrm{E}<\mathrm{e}^{-4}$.

\section{qRT-PCR.}

For qRT-PCR, first-strand cDNA was synthesized from $2 \mu \mathrm{g}$ of total DNAse-treated RNA using oligodT and SuperScript II first-strand synthesis system (Invitrogen). One-hundredth of the cDNA was used as a template in a $20-\mu l$ PCR reaction. The PCR was performed with an iCycler iQ (Bio-Rad, Hercules CA, U.S.A.) and the SYBR-GREEN Master mix (Bio-Rad) in a reaction held at $95^{\circ} \mathrm{C}$ for $5 \mathrm{~min} ; 40$ cycles of $30 \mathrm{~s}$ at $95^{\circ} \mathrm{C}, 30$ $\mathrm{s}$ at $52^{\circ} \mathrm{C}$, and $10 \mathrm{~s}$ at $72^{\circ} \mathrm{C}$; followed by $10 \mathrm{~min}$ at $72^{\circ} \mathrm{C}$. Gene-specific primers are indicated in Table 2. For each primer pair, the presence of a unique product of the expected size was checked on ethidium-bromide-stained agarose gels after PCR reactions. Absence of contaminant genomic DNA was confirmed in reactions with DNAse-treated RNA as template. Amplification of $P$. vulgaris elongation factor $1 \alpha(\mathrm{EF} 1 \alpha)$ was used to normalize the amount of template cDNA. Reproducibility of the assay was monitored by running technical triplicates, and standard error of the estimate of mean values are shown as errors bars in all figures. At least three biological replicates were performed per condition.

\section{ACKNOWLEDGMENTS}

We thank R. Chang for critical reading of the manuscript. This work was supported by grants from Agencia de Promoción Científica y Tecnológica, Argentina (PICT number 14626/03), and Volkswagen Foundation, Germany. M. E. Zanetti, F. A. Blanco, E. P. Meschini, and O. M. Aguilar were supported by the National Research Council-CONICET, Argentina.

\section{LITERATURE CITED}

Aguilar, O. M., Riva, O., and Peltzer, E.. 2004. Analysis of Rhizobium etli and of its symbiosis with wild Phaseolus vulgaris supports coevolution in centers of host diversification. Proc. Natl. Acad. Sci. U.S.A. 101:1354813553.

Altschul, S. F., Madden, T. L., Schaffer, A. A., Zhang, J., Zhang, Z., Miller, W., and Lipman, D. J. 1997. Gapped BLAST and PSI-BLAST: a new generation of protein database search programs. Nucleic Acids Res. 25:3389-3402.

Amarger, N. 2001. Rhizobia in the field. Adv. Agron. 73:109-168. 
Asamizu, E., Nakamura, Y., Sato, S., and Tabata, S. 2005. Comparison of the transcript profiles from the root and the nodulating root of the model legume Lotus japonicus by serial analysis of gene expression. Mol. Plant-Microbe Interact. 18:487-498.

Ashfield, T., Ong, L., Nobuta, K., Schneider, K., and Innes, R. 2004. Convergent evolution of disease resistance gene specificity in two flowering plant families. Plant Cell 16:309-318.

Barnett, M. J., Toman, C. J., Fisher, R. F., and Long, S. R. 2004. A dualgenome symbiosis chip for coordinate study of signal exchange and development in a prokaryote-host interaction. Proc. Natl. Acad. Sci. U.S.A. 101:16636-16641.

Becker, A., Fraysse, N., and Sharypova, L. 2005. Recent advances in studies on structures and symbiosis-related function of rhizobial K-antigens and lipopolysaccharides. Mol. Plant-Microbe Interact. 18:899-905.

Bestel-Corre, G., Dumas-Gaudot, E., and Gianinazzi, S. 2004. Proteomics as a tool to monitor plant-microbe endosymbioses in the rhizosphere. Mycorriza 14:1-10.

Borg, S., Branstrup, T. J. J., and Poulsen C. 1997. Identification of new protein species among 33 different small GTP-binding proteins encoded by cDNAs from Lotus japonicus, and expression of corresponding mRNAs in developing root nodules. Plant J. 11:237-250.

Bucher, M., Schroeer, B., Willmitzer, L., and Riesmeier, J. W. 1997. Two genes encoding extensin-like proteins are predominantly expressed in tomato root hair cells. Plant Mol. Biol. 35:497-508.

Cheon, C-.I., II, Lee, N.-G., Siddiquye, A.-B., Bal, A. K., and Verma, D. P. S. 1993. Roles of plant homologs of Rab1p and Rab7p in the biogenesis of the peribacteroid membrane, a subcellular compartment formed de novo during root nodule symbiosis. EMBO (Eur. Mol. Biol. Organ.) J. 12:4125-4135.

Colebatch, G., Desbrosses, G., Ott, T., Krusell, L., Montanari, O., Kloska, S., Kopka, J., and Udvardi, M. K. 2004. Global changes in transcription orchestrate metabolic differentiation during symbiotic nitrogen fixation in Lotus japonicus. Plant J. 39:487-512.

Combier, J. P., Frugier, F., de Billy, F., Boualem, A., El-Yahyaoui, F. Moreau, S., Vernié, T., Ott, T., Gamas, P., Crespi, M., and Niebel, A. 2006. MtHAP2-1 is a key transcriptional regulator of symbiotic nodule development regulated by microRNA169 in Medicago truncatula. Genes Dev. 20:3084-3088.

Cullimore, J. V., Ranjeva, R., and Bono, J.-J. 2001. Perception of lipo-chitooligosaccharidic Nod factors in legumes. Trends Plant Sci. 6:24-30.

de Billy, F., Grosjean, C., May, S., Bennett, M., and Cullimore, J. V. 2001. Expression studies on AUX1-like genes in Medicago truncatula suggest that auxin is required at two steps in early nodule development. Mol. Plant-Microbe Interact. 14:267-277.

Dowling, D., and Broughton, W. 1986. Competition for nodulation of legumes. Annu. Rev. Microbiol. 40:131-157.

Estrada-Navarrete, G., Alvarado-Affantranger, X., Olivares, J., DíazCamino, C., Santana, O., Murillo, E., Guillén, G., Sánchez-Guevara, N., Acosta, J., Quinto, C., Li, D., Gresshoff, P., and Sánchez, F. 2006. Agrobacterium rhizogenes transformation of the Phaseolus spp.: a tool for functional genomics. Mol. Plant-Microbe Interact. 19:1385-1393.

Fahraeus, G. 1957. The infection of clover root hairs by nodule bacteria studied by a simple glass slide technique. J. Gen. Microbiol. 16:374-381.

Gepts, P. 1998. Origin and evolution of common bean: past events and recent trends. Hortic. Sci. 33:1124-1130.

Godiard, L., Niebel, A., Micheli, F., Gouzy, J., Ott, T., and Gamas, P. 2007 Identification of new potential regulators of the Medicago truncatulaSinorhizobium meliloti symbiosis using a large-scale suppression subtractive hybridization approach. Mol. Plant-Microbe Interact. 20:321-332.

Hashimoto, H., and Yamamoto, K. 1998. An auxin down-regulated mRNA from mung bean hypocotyl (accession no. AB012110) is related to an aluminum-inducible mRNA in wheat root. Plant Physiol. 117:718.

Krause, A., Lan, V., and Broughton, W. 1997. Induction of chalcone synthase expression by rhizobia and Nod factors in root hairs and roots. Mol. Plant-Microbe Interact. 10:388-393.

Larrainzar, E., Wienkoop, S., Weckwerth, W., Ladrera, R., Arrese-Igor, C., and González, E. 2007. Medicago truncatula root nodule proteome analysis reveals differential plant and bacteroid responses to drought stress. Plant Physiol. 144:1495-1507.

Lohar, D. P., Sharapova, N., Endre, G., Peñuela, S., Samac, D., Town, C., Silverstein, K., and VandenBosch, K. 2006. Transcript analysis of early nodulation events in Medicago truncatula. Plant Physiol. 140:221-234.

Long, S. R. 1996. Rhizobium symbiosis: Nod factors in perspective. Plant Cell 8:1885-1898.

Manthey, K., Krajinski, F., Hohnjec, N., Firnhaber, C., Püuhler, A., Perlick, A., and Küster, H. 2004. Transcriptome profiling in root nodules and arbuscular mycorrhizal identifies a collection of novel genes induced during Medicago truncatula root endosymbioses. Mol. Plant-Microbe Interact. 17:1063-1077.
McKhann, H. I., Paiva, N. L., Dixon, R. A., and Hirsch, A. M. 1997. Chalcone synthase transcripts are detected in alfalfa root hairs following inoculation with wild-type Rhizobium meliloti. Mol. Plant-Microbe Interact. 10:50-58.

Melotto, M., Monteiro-Vitorello, C. B., Bruschi, A. G., and Camargo, L. E. 2005. Comparative bioinformatic analysis of genes expressed in common bean (Phaseolus vulgaris L.) seedlings. Genome 48:562-570.

Murray, J., Karas, B., Sato, S., Tabata, S., Amyot, L., and Szczyglowski, K. 2007. A cytokinin perception mutant colonized by rhizobium in the absence of nodule organogenesis. Science 315:101-104.

Oldroyd, J., Harrison, M., and Udvardi, M. 2005. Peace talks and trade deals. Keys to long-term harmony in legume-microbe symbiosis. Plant Physiol. 137:1205-1210.

Porta, H. P., and Rocha-Sosa, M. 2000. A Phaseolus vulgaris lipoxygenase gene expressed in nodules and in Rhizobium tropici inoculated roots. Biochim. Biophys. Acta 1517:1339-141.

Ramírez, M., Graham, M. A., Blanco-López, L., Silvente, S., MedranoSoto, A., Blair, M. W., Hernández, G., Vance, C. P., and Lara, M. 2005. Sequencing and analysis of common bean ESTs. Building a foundation for functional genomics. Plant Physiol. 137:1211-1227.

Rolfe, B. G., Mathesius, U., Djordjevic, M., Weinman, M., Hocart, C. Weiller, G., and Bauer, W. D. 2003. Proteomic analysis of legumemicrobe interactions. Comp. Funct. Genom. 4:225-228.

Samac, D. A., and Graham, M. A. 2007. Recent advances in legumemicrobe interactions: recognition, defense response, and symbiosis from a genomic perspective. Plant Physiol. 144:582-587.

Sambrook, J., Fritsch, E. F., and Maniatis, T. 1989. Molecular Cloning: A Laboratory Manual. Cold Spring Harbor Laboratory Press, Cold Spring Harbor, NY, U.S.A

Sánchez, L., Weidmann, S., Arnould, C., Bernard, A. R., Gianinazzi, S. and Gianinazzi-Pearson, V. 2005. Pseudomonas fluorescens and Glomus mosseae trigger DMI3-dependent activation of genes related to a signal transduction pathway in roots of Medicago truncatula. Plant Physiol. 139:1065-1077.

Song, X. F., Yang, C. Y., Liu, J., and Yang, W. C. 2006. RPA, a class II ARFGAP protein, activates ARF1 and U5 and plays a role in root hair development in Arabidopsis. Plant Physiol. 141:966-976.

Stacey, G., Libault, M., Brechenmacher, L., Wan, J., and May, G. 2006. Genetics and functional genomics of legume nodulation. Curr. Opin. Plant Biol. 9:110-121.

Subramanian, S., Stacey, G., and Yu, O. 2006. Endogenous isoflavones are essential for the establishment of symbiosis between soybean and Bradyrhizobium japonicum. Plant J. 48:261-273.

Taté, R., Patriarca, E., Riccio, A., Defez, R., and Iaccarino, M. 1994. Development of Phaseolus vulgaris root nodule. Mol. Plant-Microbe Interact. 7:582-589.

Tesfaye, M., Samac, D., and Vance, C. 2006. Insights into symbiotic nitrogen fixation in Medicago truncatula. Mol. Plant-Microbe Interact. 19:330-341.

Thies, J., Singleton, P., and Bohlool, B. 1991. Influence of the size of indigenous rhizobial population on establishment and symbiotic performance of introduced rhizobia on field-grown legumes. Appl. Environ. Microbiol. 57:19-28.

Tirichine, L., Sandal, N., Madsen, L., Radutoiu, S., Albrektsen, A., Sato, S., Asamizu, E., Tabata, S., and Stougaard, J. 2007. A gain-of-function mutation in a cytokinin receptor triggers spontaneous root nodule organogenesis. Science 315:104-107.

van Noorden, G., Ross, J., Reid, J., Rolfe, B., and Mathesius, U. 2006. Defective long distance auxin transport regulation in the Medicago truncatula supernumerary nodules mutant. Plant Physiol. 140:1494-1506.

Wan, J., Torres, M., Ganapathy, A., Thelen, J., DaGue, B., Mooney, B., Xu, D., and Stacey, G. 2005. Proteomic analysis of soybean root hairs after infection by Bradyrhizobium japonicum. Mol. Plant-Microbe Interact. 18:458-467.

Wasson, A., Pellerone, F., and Mathesius, U. 2006. Silencing the flavonoid pathway in Medicago truncatula inhibits root nodule formation and prevents auxin transport regulation by rhizobia. Plant Cell 18:1617-1629.

Yahyaoui, F., Küster, H., Amor, B., Hohnjec, N., Pühler, A., Becker, A., Gouzy, J., Vernie, T., Gough, C., Niebel, A., Godiard, L., and Gamas, P. 2004. Expression profiling in Medicago truncatula identifies more than 750 genes differentially expressed during nodulation, including many potential regulators of the symbiotic program. Plant Physiol. 136:3159-3176.

\section{AUTHOR-RECOMMENDED INTERNET RESOURCE}

TIGR P. vulgaris Gene Index: www.tigr.org

PHASEOMICS Global Initiative: www.phaseolus.net 